\title{
INFÂNCIA E POLÍTICAS PÚBLICAS: UM OLHAR SOBRE AS PRÁTICAS PSI
}

\author{
Lílian Cruz \\ Betina Hillesheim \\ Universidade de Santa Cruz do Sul \\ Neuza Maria de Fátima Guareschi \\ Pontifícia Universidade Católica do Rio Grande do Sul
}

RESUMO: Este artigo objetiva discutir, a partir das formas pelas quais se constituiu a categoria infância no Brasil, a atual configuração das políticas públicas voltadas para essa área, especialmente no que se refere às práticas da Psicologia. Entendemos a infância como uma construção social, isto é, como uma noção datada geográfica e historicamente. Apontamos como a Psicologia se faz presente em temáticas, tais como o estabelecimento de padrões de normalidade e anormalidade, circunscrevendo etapas evolutivas em relação à infância. Como exemplo, citamos o Juizado de Menores, o Serviço de Assistência do Menor (SAM) e as Fundações Estaduais do Bem-Estar do Menor (FEBEMs), bem como as atuais entidades de abrigos, já reordenadas a partir do Estatuto da Criança e do Adolescente (ECA). Para finalizar, problematizamos a inserção da Psicologia no debate sobre as políticas públicas, especificamente na área da infância denominada vulnerável.

PALAVRAS-CHAVE: infância; políticas públicas; práticas psicológicas.

\section{PSYCHOLOGICAL PRACTICES AND PUBLIC POLICIES FOR CHILDHOOD}

ABSTRACT: This paper aims to discuss the current configuration of public policies, especially from the psychological practices, based on the ways the childhood category was created in Brazil. Childhood is understood as a social construction, meaning here a geographic and historical knowledge's schedule. By the setting of some disciplinary approaches, Psychology is highlighted in themes as such as patterns of normality and abnormality connected to evolution steps with the childhood. As examples the Juizado de Menores, the Serviço de Assistência do Menor (SAM) and the Fundações Estaduais do Bem - Estar do Menor (FEBEMs) as well as the current shelters reorganized from the Estatuto da Criança e do Adolescente (ECA) can be pointed. So, a problematization about the interplay of the Psychology on the public policies debate about the way childhood's vulnerability was proposed.

KEY WORDS: childhood; public policies; psychological practices.

Este artigo objetiva discutir, a partir das formas pelas quais se constituiu a categoria infância no Brasil, a atual configuração das políticas públicas voltadas para essa área, especialmente no que se refere às práticas da Psicologia. Entender a infância como uma noção datada geográfica e historicamente - e não uma etapa natural da vida - implica em trazer para o debate questões relativas à família, aos vínculos mães/pais/filhos/filhas, à escola, à maternidade/paternidade, às formas de criação de filhos, etc. Portanto, ao falar em infância não remetemos a uma abstração, mas a uma construção discursiva que institui determinadas posições - não só das crianças, mas também da família, dos pais, das mães, das instituições escolares, entre outros, instituindo determinados modos de ser e viver a infância e não outros. Como assinala Bujes (2000), à invenção da infância associam-se formas de intervenção social, implicadas em práticas de regulação e controle. Nesta perspectiva, apontamos que a Psicologia se faz presente em todas estas temáticas, estabelecendo, por exemplo, padrões de normalidade e anormalidade, circunscrevendo etapas evolutivas (tanto individuais quanto do grupo familiar), consolidando as práticas escolares de classificação e ordenação das crianças conforme seus desempenhos ou prescrevendo determinados cuidados que devem ser dispensados às crianças.
A partir destas considerações iniciais, voltamo-nos para as políticas sociais públicas direcionadas à área da infância no Brasil, compreendendo que sua implementação, ao mesmo tempo em que se relaciona com o conhecimento que é produzido sobre a infância por uma determinada construção histórica, também produz essa infância a que se propõe conhecer. Dito de outro modo, as políticas públicas vêm constituir determinadas formas de ser criança e de se relacionar com as mesmas.

\section{A Infância como Alvo das Políticas Públicas}

Ao pensarmos em ações voltadas à infância no Brasil, convém destacarmos que a Roda dos Expostos $^{1}$ foi a

${ }^{1}$ As rodas de expostos tiveram origem na Idade Média, na Itália. Elas surgiram no século XII com a aparição das confrarias de caridade, que prestavam assistência aos pobres, aos doentes e aos expostos. As rodas eram cilindros rotatórios de madeira usados em mosteiros como meio de se enviar objetos, alimentos e mensagens aos seus residentes. Rodava-se o cilindro e as mercadorias iam para o interior da casa, sem que os internos vissem quem as deixara. A finalidade era a de se evitar o contato dos religiosos enclausurados com o mundo exterior, garantindo-lhes a vida contemplativa. Como os mosteiros medievais recebiam crianças doadas por seus pais, para o serviço de Deus, muitos pais que "abandonavam" seus filhos utilizavam a roda dos mosteiros para nela depositarem o bebê. Desse uso indevido das rodas dos mosteiros, surgia o uso da roda para receber os expostos, fixada nos muros dos hospitais para cuidar das crianças abandonadas. Assim, o nome da roda provém deste dispositivo (Marcílio, 1999). 
primeira instituição oficial de assistência à criança abandonada no país. A Roda constituiu-se como uma das instituições brasileiras de maior duração, tendo sido criada no período colonial e sendo extinta apenas na década de 1950. Importante salientar que esta tinha a intenção de manter o sigilo/segredo do expositor, assim como o anonimato e o destino das crianças (Marcílio, 1999; Venâncio, 1999).

Assistir às crianças abandonadas era uma incumbência aceita com muita resistência pelas Câmaras. Desta forma, estas conseguiram fazer aprovar uma lei chamada "Lei dos Municípios”, em 1828, em que abria a possibilidade de eximir algumas Câmaras dessa pesada obrigação. Assim, "em toda a cidade onde houvesse uma Misericórdia, a Câmara poderia usar de seus serviços para a instalação da Roda e assistência aos enjeitados que recebesse" (Marcílio, 1999, p.60), sendo que a parceria se daria com a Assembléia Legislativa Provincial. A autora enfatiza que, com isto, perdia-se o caráter caritativo da assistência, para inaugurar sua fase filantrópica, associando-se o público e o privado. Salienta-se que esta lei também foi feita para incentivar a iniciativa particular a assumir a tarefa de criar as crianças abandonadas, liberando as municipalidades deste serviço. Neste momento, identificamos as primeiras alianças entre caridade e governo, onde a caridade toma a iniciativa e o governo entra com a verba para a manutenção dos estabelecimentos criados. Logo, constatamos que as alianças/parcerias entre Estado e sociedade civil são antigas e atravessam a história, onde a Igreja católica marca significativa presença.

Entretanto, é no século XIX que a infância começa a ganhar visibilidade, sendo definida como objeto de ação e intervenção públicas em todo o Ocidente, uma vez que as preocupações relativas à preservação e à reserva de mão-de-obra começam a integrar o cenário social e político (Silva Santos, 2004). Segundo a autora, eram preocupações de origem européia, que foram trazidas com a vinda da Família Real, como os conceitos de trabalho como valor positivo e enobrecedor. Estes conceitos contrastaram com o traço demeritório do trabalho brasileiro, associado aos escravos e às pessoas sem valor na escala social. Para transformar em qualidade o que era percebido como defeito, o poder soberano começou a interferir nos paradigmas sócio-familiares. Para tal, acionou um conjunto de saberpoder, como definido por Foucault ${ }^{2}$. Estes se pautaram na introdução das idéias higienistas e eugênicas ${ }^{3}$.

Assim o período compreendido entre o fim do século XIX e início do século XX caracteriza-se pela introdução das idéias higienistas e eugênicas no país. Nesta época,

\footnotetext{
${ }^{2}$ Foucault (1984) problematiza a concepção de neutralidade dos sistemas de conhecimento que para ele estão sempre relacionados com a história da modificação do poder. Assim, as formas de identificação da loucura, sexualidade, etc., não são homogêneas no decorrer da história, mas estão articuladas à emergência de novas formas de funcionamento da sociedade.

${ }^{3}$ Essas idéias não são equivalentes, mas complementares. A primeira, tendo como pressuposto a sanidade, o controle de doenças e epidemias, servindo quase que como padrão estético, como sinônimo de limpo, higidez. Já a segunda, caracterizando uma crença numa raça superior, numa humanidade racial, servindo de fator de inclusão ou exclusão social pela condição étnica/racial.
}

embora o monopólio no atendimento a menores ainda fosse de entidades privadas, percebe-se o fomento da participação do Estado nesse campo. Cabe assinalar aqui o uso do termo 'menores', o qual remete a uma concepção de infância enquanto menoridade e relacionada a questões de responsabilidade penal. Segundo Bulcão (2002), a preocupação em criar ações voltadas para o atendimento de crianças e adolescentes neste momento, vinculava-se especialmente com a visibilidade de um grande contingente desta população vivendo nas ruas das grandes cidades, como resultado de mudanças econômicas e políticas, como o fim do regime de trabalho escravo e a imigração de trabalhadores europeus, acompanhados de um estreitamento do mercado de trabalho e um crescimento desordenado das áreas urbanas. Desta forma, os chamados menores tornaram-se um problema do poder público. As medidas higiênicas, visando tirar as crianças das ruas e interná-las em instituições apropriadas, denominadas casas de correção, tinham como método a educação pela disciplina do trabalho (Martins \& Brito, 2001).

Neste sentido, percebe-se a preocupação com a gestão e a tutela dos chamados perigosos, instituindo-se a noção de periculosidade. Deste modo, segundo Foucault (1996), os indivíduos passam a ser considerados pela virtualidade de seus comportamentos e não por infrações efetivas. A partir desta noção, formam-se uma série de instituições nomeadas instituições de seqüestro, cuja finalidade é fixar os indivíduos a aparelhos de normatização, buscando enquadrá-los e controlá-los ao nível de suas virtualidades. Tais formas de organização e controle da sociedade são características do que Foucault convencionou chamar de "sociedade disciplinar", onde um dos pilares desta é a vigilância. Desta forma, o discurso do modelo disciplinar é fundado na norma, produzindo uma sociedade de normalização, na qual existe um grupo humano cujos limites variam de acordo com os outros. Essa norma serve para que o indivíduo possa balizar seu comportamento pelo comportamento "médio", codificado como "normal".

A preocupação com a prevenção insere-se neste cenário, o qual busca a vigilância do que pode ser potencialmente perigoso. Um dos fundamentos da idéia de prevenção neste contexto apóia-se na eugenia, com a noção de que a purificação da raça evitaria os caracteres nocivos presentes nas "raças inferiores", entendidas aqui especialmente como negros e mestiços. Esta preocupação estava relacionada com o inchaço das cidades e os riscos que o aumento da população urbana ocasionava à saúde. Com isto, há uma reorganização da Medicina, que desloca seu foco da doença para a saúde, aumentando sua entrada na sociedade, bem como sendo utilizada como apoio técnico-científico ao exercício do poder do Estado e de diferentes micro-poderes.

Bulcão (2002) refere que a higiene se fez presente através do saber médico, onde a preocupação era higienizar os espaços públicos para poder melhor controlálos. Contudo, a limpeza das cidades passava pelos hábitos e comportamentos das famílias, tornando urgente a intervenção dos médicos nesse campo, criando a necessidade de uma educação sanitária para as famílias. 
A preocupação dos médicos com os altos índices de mortalidade infantil fez com que estes direcionassem as campanhas para a formação de um novo modelo familiar. Neste sentido, aponta-se para a redefinição do papel da mulher, uma vez que, através do discurso da valorização desta, visavam convencê-la da importância do cuidado permanente e direto com os filhos. O discurso científico foi utilizado para persuadir a mulher de sua responsabilidade pela felicidade do lar. A estratégia era tomar a mulher como alvo para atingir toda a família, especialmente as crianças.

Para Corazza (2000), a infância constituiu-se como prática discursiva e não-discursiva a partir de "novas práticas de biopoder, ligadas aos emergentes mecanismos de governamentalidade das populações e dos indivíduos" (p.224). A preocupação com o sujeito infantil, portanto, passava a se instituir cada vez mais como um problema econômico e político, alvo de inquietações de ações médicas, morais e pedagógicas.

Associada à intervenção da Medicina, o campo do Direito também se voltou para a infância, visto que o grande número de crianças que perambulavam pelas ruas passou a ser compreendido como causa do aumento da criminalidade. Conforme Frota (2003), o primeiro código de menores brasileiro data de 1927, sendo destinado aos menores de 18 anos classificados como em situação irregular ${ }^{4}$. Este código delegava aos estados a responsabilidade pela execução do atendimento de crianças e adolescentes, caracterizando-se por uma intervenção ativa dos mesmos no controle da população carente.

A infância tornou-se objeto dos juristas, sendo que neste período o termo 'menor' foi incorporado ao vocabulário corrente (Bulcão, 2002; Rizzini \& Pilotti,1995). Para Rizzini e Pilotti (1995), não houve nenhum tipo de problematização no que se refere à categoria 'menor', a qual incluía as seguintes classificações: abandonado, delinqüente, desviado e viciado.

Também a psicologia e a pedagogia se organizaram com o propósito de estabelecer uma nova educação que possibilitasse a produção de um novo cidadão e o assentamento de uma nova raça: sadia e ativa. Desta maneira, na década de 1920 disseminaram-se as campanhas e reformas sob a denominação de "Movimento da Escola Nova". É importante salientar que a Escola Nova valorizava o discurso científico, especialmente os advindos dos estudos da Psicologia, com o objetivo de melhor conhecer aquela a quem se pretendia ensinar: a criança. Podemos dizer que a psicologia, no Brasil, se insere na área da educação entre 1931 e 1934, tomando as crianças como objeto psico-médico-biológico, passíveis de serem medidas, testadas, ordenadas e denominadas normais e anormais. Pinto (2003) afirma que as mudanças em relação às escolas tiveram uma intenção prioritariamente

\footnotetext{
${ }^{4}$ Duas categorias de crianças e adolescentes eram consideradas como em situação irregular: 1) delinqüentes, isto é, aqueles que haviam cometido algum ato infracional; e 2) abandonados, ou seja, aqueles que eventualmente se encontravam sem moradia fixa ou cujos responsáveis legais tivessem condutas tidas como contrárias à moral ou aos bons costumes.
}

disciplinar. Desta forma, a psicologia, ancorada em estudos experimentais e de observação de crianças, vinha reforçar as noções de variabilidade entre os indivíduos e de capacidades individuais diferenciadas. A Psicologia apresentava-se, portanto, como capaz de delimitar as causas dos desvios de conduta, através do uso de testes e da análise da personalidade infantil, possibilitando ações preventivas e de correção das mesmas. Citamos como exemplo desta prática o Laboratório de Biologia Infantil, órgão anexo ao Juizado de Menores, o qual foi proposto em 1935 e passou a funcionar no ano seguinte.

Este Laboratório tinha como objetivo auxiliar o Juizado nas funções de abrigar e distribuir as crianças que necessitavam de proteção e assistência pelas diversas instituições disponíveis. Assim, destinava-se a "fornecer as bases científicas para o tratamento médico-pedagógico da infância abandonada e delinqüente" (Oliveira, 2001, p.238). Ou seja, acreditava-se que o mesmo modelo científico - de classificação - poderia transformar o aparelho assistencial, solucionando o "problema da infância". Neste sentido, a psicologia apresentava-se como um dos instrumentos capazes de determinar as causas do desvio do menor. Assim, a "investigação dos interesses e do senso ético de crianças e jovens seria feita mediante o uso de testes, objetivando não só classificar, mas resgatar o desviante, enquadrando-o à normatividade dos registros da mão-de-obra infantojuvenil" (Oliveira, 2001, p.240). Desta forma, os saberes científicos, especificamente o pensamento psicológico, legitimou atitudes de exclusão e desqualificação de crianças e jovens pobres e delinqüentes, uma vez que fez (ou ainda faz) recair a terapêutica sobre o indivíduo desviante, esvaziando discussões quanto aos aspectos sociais que compõe o desvio.

Martins e Brito (2003) apontam que a função primordial na vigência da Doutrina da Situação Irregular era a produção de relatórios técnicos, nos quais enfocavam a etiologia da infração e as causas da suposta "desagregação familiar" destes sujeitos. Os laudos daquele período reproduziam o padrão das elites sociais no que diz respeito à família, trabalho e moradia. Assim, a família era encarada como um pilar para a recuperação dos jovens denominados "infratores". Contudo, o modelo hegemônico espelhava-se na família nuclear burguesa, sendo que, por exemplo, no caso de um jovem não contar com a presença do pai na família, esta já era considerada como desagregada ou desestruturada. Evidencia-se que o fator determinante que permitia incluir (ou excluir) estes jovens em certas medidas de re-socialização era a origem sócio-econômica de suas famílias.

Dentre os esforços para definir políticas sistemáticas de intervenção, com o intuito de "recuperar" e "reintegrar"

\footnotetext{
${ }^{5}$ Utilizamos aqui o termo largamente empregado nos campos da Psicologia, do Serviço Social, da Pedagogia, entre outros, para se referir a famílias que não correspondem ao modelo hegemônico, o que seria causa, no entender de determinados teóricos, de problemas/transtornos/desvios diversos em relação a seus membros. Tal termo costuma ser usado de forma naturalizada, isto é, parte-se da compreensão que existe um modelo familiar ideal, o qual deve necessariamente ser desta forma para que seus membros possam ter um desenvolvimento tido como 'saudável' e 'normal'.
} 
os jovens ao meio social, foi fundado o Serviço de Assistência do Menor (SAM), em 1942. Junto a este surgem os reformatórios, que abrigavam - sob regime disciplinar - "menores delinqüentes". A estrutura dos reformatórios era análoga ao sistema penitenciário (Martins \& Brito, 2001). Assim, a disciplina e o trabalho eram os meios empregados para corrigir condutas que respondiam a defeitos morais. Os idealizadores e defensores do SAM acreditavam que o modelo repressivo, bem como a contenção, faria extinguir a criminalidade. Entretanto, as crianças e adolescentes autores de atos infracionais que chegassem ao Juizado eram considerados delinqüentes natos, indivíduos de má índole e dotados de alto grau de periculosidade. As instituições corretivas, "sob o manto de uma proposta pedagógica adaptacionista, ou, mais tarde, reabilitadora, apenas institucionalizavam a exploração da mão-de-obra de crianças e adolescentes pobres, inviabilizados pela lei” (p.246).

Com o Golpe Militar de 1964, o SAM foi extinto, instrumentalizando-se de fato a intervenção pública sobre as crianças e adolescentes, através da Política do BemEstar do Menor (PNBEM) e, posteriormente, o Código de Menores. A partir do pressuposto de que o "menor" com conduta anti-social era considerado como um ser "doente" que necessitava de "tratamento", a ação corretiva da FUNABEM fundamentou-se em métodos terapêuticos - pedagógicos desenvolvidos com a finalidade de possibilitar a "reeducação" e a "reintegração" do "menor" à sociedade. A FUNABEM voltava-se para a utilização de políticas de prevenção capazes de evitar que o "menor" incorresse no processo que levaria à marginalização, à medida que a marginalidade representava um fator de risco para a ordem e paz social. Assim, através da FUNABEM, o infrator teria acesso a um modelo educativo não-repressivo. Acreditava-se que o tratamento "biopsicossocial" reverteria a "cultura da violência" que se propagava pelos subúrbios com os conflitos entre gangues e com isso contribuiria para acabar com a marginalidade, formando jovens responsáveis para a vida em sociedade (Passetti, 1999).

A partir do processo de abertura política, a PNBEM começou a sofrer severas críticas, sendo a FUNABEM identificada como uma escola do crime. Tornava-se visível a eficiência do Estado na produção de menores abandonados, menores de rua, menores em situação de risco, mediante políticas/práticas de exclusão social. Para modificar essa imagem, o discurso terapêutico começou a ser substituído pelo da prevenção (Ayres, 2001).

Concomitantemente, os especialistas da área social ganhavam visibilidade. Segundo Coimbra (1995), através de seus saberes, muitos destes desqualificaram a vida de crianças pobres, interferindo (ou até determinando) em seus destinos, na medida em que apontavam para uma estreita conexão entre a criminalidade e a pobreza. A diferença é que a penalização - nas décadas de 1970 e 80 era sustentada pelo discurso dos especialistas, o qual atestava o fracasso da família no atendimento à prole. A autora salienta que, nos anos 1970 , as práticas psicológicas eclodiram no país de forma distanciada dos chamados novos movimentos sociais, fortalecendo as subjetividades hegemônicas produzidas no período. Coimbra e Leitão (2003) lembram que, na Doutrina de Segurança Nacional, tudo que escapasse às formas de interiorização naturalizadas era considerado perigoso, e, assim, deveria ser banido. Desta forma, duas categorias sobre a juventude foram produzidas: a do subversivo e a do drogado. Tas categorias escapavam ao modelo de família sadia e estruturada e com sonhos de ascensão social, sendo que as práticas psi ajudaram a fortalecer as crenças nos modelos e nas homogeneidades.

Ayres (2001) salienta que a prática de desqualificação realizada pelos técnicos do Juizado (psicólogos e assistentes sociais) legitimava os motivos da família quanto à desistência do pátrio poder ${ }^{6}$, supondo a pobreza como natural e imutável, bem como associada à incapacidade para assistir os filhos. Para Silva (1998), o princípio da destituição do pátrio poder6 afirmou-se neste período e que a sentença de abandono retirou a criança da responsabilidade dos pais, da comunidade e da sociedade, transferindo-a para o Estado. Essa condição jurídica da criança justificou sua internação até os 18 anos - a institucionalização propriamente dita - e configurou a categoria de crianças denominada filhos do Governo.

Considerando-se tais questões, bem como a divulgação e a repercussão dos dados da própria FUNABEM (a cada dois brasileiros menores de 19 anos, pelo menos um encontrava-se em situação de carência) outra estratégia de assistência à população infanto-juvenil foi sendo gestada (Pinheiro, 2001). Durante as décadas de 1960 e 70 , foram elaborados diferentes projetos de alteração do Código de Menores, sendo que estes se dividiam em duas posições no que se refere à Declaração Universal dos Direitos da Criança, aprovada Pela Assembléia Geral das Nações Unidas, em 1959: uma favorável à inclusão de seus dez princípios na legislação brasileira e outra contrária a esta inclusão. O Código de Menores de 1979 representou a posição contrária à inclusão dos princípios formulados pela Declaração dos Direitos da Criança de 1959, baseando-se na mesma doutrina da situação irregular que pautava o código anterior (Frota, 2003)7. A autora aponta que, neste Código, não há distinção entre crianças e adolescentes (todos são agrupados sob a categoria menor), sendo que os mesmos não são definidos como sujeitos de direitos, não havendo menção a deveres do Estado ou da sociedade, nem penalidades previstas para quem cometer atos de violências contra crianças e adolescentes. São consideradas infrações somente aspectos referentes à divulgação de dados e imagens, freqüência a determinados lugares ou o descumprimento de deveres relativos ao pátrio poder por parte dos responsáveis legais.

Na década de 1980, as discussões sobre a temática da infância e juventude tiveram influência direta das normativas internacionais. Em 1985, com a edição das

\footnotetext{
${ }^{6}$ Deve-se assinalar que, a partir do Novo Código Civil (2002), esta expressão foi substituída por destituição do poder familiar.

${ }^{7}$ Volpi (1994) também se refere a duas visões antagônicas em relação ao trabalho com a infância marginalizada, até o final da década de 1970. Uma de caráter repressivo e assistencialista e outra, que surgia dos movimentos populares, em defesa dos direitos dos jovens.
} 
Regras Mínimas das Nações Unidas para a Administração da Justiça da Infância e da Juventude Regras de Beijing-Pequim -, são estabelecidas exigências procedimentais, com o objetivo de diminuir a arbitrariedade na aplicação de medidas aos infratores juvenis. O documento normativo de maior relevância, nesse âmbito, é a Convenção sobre Direitos da Criança de 1989, que incorpora a Doutrina da Proteção Integral ${ }^{8}$.

Como resultado de toda essa articulação, foi sancionado o Estatuto da Criança e do Adolescente (ECA), o qual estabeleceu o caminho para a intervenção popular nas políticas de assistência, traçando as diretrizes da política de atendimento: criação de conselhos municipais, estaduais e nacionais dos direitos da criança e do adolescente, órgãos deliberativos e controladores das ações em todos os níveis, assegurando-se a participação popular paritária por meio de organizações representativas, segundo leis federal, estaduais e municipais. Inicia-se aqui uma nova fase, desinstitucionalizadora, caracterizada pela implementação de uma nova política que amplia quantitativa e qualitativamente a participação da sociedade na elaboração, deliberação, gestão e controle das políticas para a infância, o que é fundamental para a garantia da implementação da Lei (Brasil, 1990).

Tendo traçado até aqui a trajetória das políticas públicas direcionadas à infância em nosso país, das práticas higienistas-eugênicas à formulação do ECA, considerado um avanço na constituição deste espaço, cabe discutirmos, a seguir, algumas implicações disto para as práticas psi. Como estas compreendem/ descrevem/ produzem a categoria infância, em especial a infância pobre?

\section{Práticas Psicológicas e Políticas Públicas para a Infância}

Ao analisar o período de 1985 e 1994 (transição entre o Código de Menores e o ECA), Ayres (2002) conclui que a posição do psicólogo como especialista perito é ratificada, na medida em que seus discursos autorizados pela cientificidade acabam por conferir uma essência às formas alternativas de convivência familiar, pelo deslocamento do foco de questões sociais para os aspectos individuais. As questões sociais são descontextualizadas, sendo que o discurso dos especialistas fragmenta o sujeito em dois pólos distintos, ainda que tangenciados: indivíduo e sociedade. A prática psi hegemônica sustenta-se, assim, em determinadas ferramentas teóricas que produzem a naturalização da perda do vínculo familiar em famílias pobres. Nas

\footnotetext{
${ }^{8}$ As discussões para a formulação desta transcorreram por uma década, desencadeadas a partir de 1979, Ano Internacional da Criança, com o objetivo de atualizar a Declaração Universal dos Direitos da Criança, de 1959. A Doutrina afirma o valor intrínseco da criança como ser humano; a necessidade de especial respeito à sua condição de pessoa em desenvolvimento; o valor prospectivo da infância e da juventude, como portadoras da continuidade do seu povo, da sua família e da espécie humana e o reconhecimento de sua vulnerabilidade, o que torna as crianças e os adolescentes merecedores de proteção integral por parte da família, da sociedade e do Estado, o qual deverá atuar através de políticas específicas para o atendimento, promoção e a defesa de seus direitos (Gomes da Costa, 1993).
}

palavras de Gomes e Nascimento (2003): "tal como os médicos-higienistas e os juristas do início do século, alguns dos atuais técnicos recomendam medidas disciplinares aos desviantes e o fazem apoiados em um saber científico, tido como inquestionável” (p. 323).

Lembremos que as relações de poder são múltiplas e atravessam a produção do conhecimento, não havendo poder sem a constituição de um campo de saber (Foucault, 1996). Os saberes são compreendidos como dispositivos políticos articulados com as estruturas sociais. Os efeitos de verdade não podem ser concebidos dissociados do poder e dos mecanismos de poder, visto que, como alerta Foucault (2003), esses mecanismos tanto tornam possíveis as produções de verdade, quanto essas têm efeitos de poder, entrelaçando-se, assim, verdade/poder, saber/ poder. Voltando-nos para as práticas psi direcionadas à área da infância, podemos perceber que à psicologia é endereçada uma solicitação dicotomizada: individual/ social; normal/patológico; família estruturada/ desestruturada. Deste modo, as práticas psi apóiam-se fortemente em concepções naturalistas do conhecimento, calcadas na objetividade e neutralidade. O discurso científico vem produzir subjetividades desqualificadas famílias incompetentes e negligentes - colocando os sujeitos em uma posição de tutela em relação ao conhecimento dos especialistas, em especial do campo da Psicologia. As práticas psi, ao constituírem uma infância tida como ideal, desejável, normal, produzem assim uma verdade sobre determinados modos de ser e viver a infância.

Entendemos ainda que, embora o ECA incorpore uma série de questionamentos em relação às políticas sociais para a infância ${ }^{9}$, podemos dizer que perdura uma noção compensatória no que se refere às crianças e adolescentes pobres, ou seja, estes são compreendidos como carentes e em situação de risco. Constrói-se, assim, uma infância dita 'normal' em oposição a uma infância de risco, o que se entrelaça com a noção de uma essência infantil, vista como natural e, portanto, fixa e imutável. Deste modo, na medida em que se pretende igualar infâncias desiguais tomando-se aqui a classe social como foco de análise sua lógica é formulada dentro de princípios científicos que historicamente caracterizam as crianças a partir de um modelo hegemônico, integrando-se aos valores defendidos pelo liberalismo.

Os fins protetores da lei parecem estar sendo exercidos através de maior controle social, contudo, apenas quando há visibilidade. Neste sentido, embora dirigido a todas as crianças, apenas as pobres chegam ao conselho tutelar vítimas de maus-tratos e negligência familiar, o que leva a pensar que, na inexistência de carência material, não se dá visibilidade a esta questão. Mesmo que o ECA afirme que a criança não possa ser retirada de sua família por motivo sócio-econômico, no cotidiano o quesito pobreza ainda determina os motivos de abrigamentos. Em um levantamento recente feito em um abrigo governamental

${ }^{9}$ Podemos apontar, entre outros avanços, o reconhecimento das crianças e adolescentes como sujeitos de direitos e a substituição do termo 'menor' por crianças e adolescentes, buscando uma descriminalização da infância e juventude pobres. 
da Fundação de Proteção Especial, constatou-se que 78\% dos motivos de ingressos referiam-se a negligência dos pais (Santos, 2004). Considerando que $22 \%$ das famílias vivem com renda per capita inferior a $1 / 4$ do salário mínimo ${ }^{10}$

, como as famílias poderiam assegurar os direitos de acesso à saúde, educação, alimentação, esporte e lazer, conforme disposto no artigo 4? Quem está sendo negligente? A família ou o Estado? Para Fajardo (2002), o ECA parece expressar este limite ao positivar como fundamentais muitos direitos econômicos, sociais e culturais, sem ter-se preocupado em normatizar as condições de fato para sua garantia material. Assim, o estatuto limita-se a afirmar direitos e a atribuir responsabilidades, distribuídas entre a família, a sociedade e o Estado. Portanto, não entra na lógica do possível, apenas enfatiza os direitos da criança como prioridade absoluta.

Além disto, ao afirmar as crianças como seres em desenvolvimento, a infância é tomada a partir da ótica adulta, isto é, como uma etapa de vida a ser superada e que necessita proteção integral, na medida em que é compreendida como frágil e incapaz. Coimbra e Nascimento (2004) referem que, apesar dos inegáveis avanços representados pelo ECA, a própria definição de crianças e adolescentes como sujeitos de direitos tidos como inerentes à pessoa humana, isto é, universais, relacionase também a uma proposta liberal (principalmente a partir do pressuposto da igualdade), que os caracteriza como portadores de uma determinada essência. Ao tratar os conceitos infância e família como universais, o ECA desconsidera outras formas de ver e viver a infância, assim como outros modos de sociabilidade.

Para ilustrar, trazemos a discussão de Fonseca (1999), que critica as práticas profissionais calcadas em modelos familiares (usualmente importados) que pouco auxiliam a entender a realidade de grupos populares no Brasil. Nesses grupos, por exemplo, as redes de ajuda mútua e as lealdades duradouras se explicam através do 'sangue'. A autora sugere que descolonizemos o olhar para reconhecer que numa mesma sociedade complexa, podem coexistir diversas configurações familiares - cada uma com uma lógica interna. Como exemplo, podemos trazer a chamada "circulação de crianças" em famílias brasileiras (Fonseca, 1995). Esta se refere a uma tradição histórica conforme a qual as crianças transitam entre diferentes mães, tais como avó, madrinha, mãe biológica e até vizinha. A partir disto, poder-se-ia imaginar que o ECA, ao tratar de modalidades de família substituta (seção III, art. 28-52), contemplasse estes casos. Não há, porém, nenhuma referência a tal prática. As sessões que versam sobre guarda e tutela ocupam pouco espaço no texto do estatuto, havendo uma evidente valorização do tema referente à adoção plena (Fonseca, 2004).

Outro exemplo refere-se às questões que envolvem crianças e adolescentes autores de atos infracionais. Em Porto Alegre, a FEBEM deixou de existir em 2000. O

${ }^{10}$ Dados extraídos do VII Encontro Nacional de Articulação do Conselho Nacional dos Direitos da Criança - CONANDA, 2004. Painel intitulado: Infância brasileira: breves comentários sobre o contexto atual, apresentado por Renato Roseno. atendimento foi dividido, novamente, em duas categorias: a Fundação de Proteção Especial (FPE), que se volta para as crianças e os adolescentes que precisam de proteção e a Fundação de Atendimento Sócio-educativo (FASE), a que compete os adolescentes em conflito com a lei. Este é um campo de permanente tensão. Tensão que se acirra quando acontece uma rebelião na FEBEM de São Paulo, por exemplo, retornando propostas de retrocesso legal, como a redução da idade penal, bem como a defesa de um sistema prisional para adolescentes semelhantes aos dos adultos.

No que diz respeito à aplicação de medidas sócioeducativas, estas não são atribuições do Conselho Tutelar, mas permaneceram como competência do Juizado da Infância e Juventude. Além desta divisão de origem, podemos lembrar a distinção histórica entre as categorias "menor" e "criança" e nos interrogarmos se a criação de um Juizado específico para examinar os processos de adolescentes em conflito com a lei (como é o caso de Porto Alegre) não é uma forma de perpetuação da clássica divisão entre as crianças que precisam de proteção e as que precisam de correção, uma vez que remete o jovem autor de ato infracional para um atendimento jurídico diferenciado. Junto a isto, nos deparamos com o fato de que o adolescente infrator é ainda aquele pertencente a um grupo social específico, originário das favelas, ao passo que adolescente da classe média/alta, quando comete delitos, tem destino singular, tanto no que se refere à cobertura da mídia sobre o assunto, quanto à aplicação das penas.

A partir disto, consideramos que, embora o ECA possibilite um prisma diferente sobre a infância em relação às leis que o antecederam, esta continua sendo compreendida no singular, delineando modos de viver, sentir e agir e posicionando crianças e adultos como sujeitos em suas comunidades, a partir da determinação de direitos e deveres para uns(as) e outros(as). Neste sentido, Vianna (2002) alerta para a tensão entre a tradição universalizante dos direitos humanos e as diferenças entre os sujeitos, em termos de classe social e referências culturais ${ }^{11}$.

\footnotetext{
${ }^{11}$ Segundo Vianna (2002), “a tensão entre o 'universal' da infância como valor e o 'específico' cultural ou social das infâncias concretas tem sido tematizada em relatórios internacionais, como os produzidos pelo European Centre Childhood Programme, que relatam o resultado de encontros entre representantes de 16 países durante os anos 1987, 1990, 1992 e 1993, buscando chegar a princípios comuns de análise e de ação a partir das diferentes realidades nacionais retratadas, ou em publicações realizadas, como o periódico Chilldhood - A Global of Child Research, que dedica parte de suas edições a temas como o choque cultural entre crianças de minorias étnicas ou imigrantes e as regulações nacionais às quais estão legalmente submetidas" (p.302). A autora cita os trabalhos de Sharon Stephens, "que têm chamado a atenção para o fato de que, por serem tomadas também como símbolos de futuro e objetos de políticas culturais, as crianças permanecem na encruzilhada de projetos culturais divergentes. A natureza de seus sentidos, linguagens, redes sociais, visões de mundo e futuro material é base de debates sobre pureza étnica, identidade nacional, auto-expressão minoritária e autogestão, de modo que discutir critérios culturais de definição de infância significa necessariamente problematizar a questão das fronteiras no mundo contemporâneo e, conseqüentemente, colocar em discussão o próprio conceito de cultura" (p. 302).
} 
A doutrina de proteção integral é clara em relação a seu destinatário - a criança e o adolescente -, mas não em relação ao seu método nem aos objetivos - como e por que agir. Pode-se apontar a ambigüidade do estatuto, visto que, ao mesmo tempo em que conceitua a criança e o adolescente como sujeitos de direito, o que pressupõe uma ênfase na autonomia, também se apóia em um enfoque intervencionista, tutelar (Fajardo, 2002).

Analisar o ECA significa, portanto, perguntar sobre a infância que este produz e sobre os efeitos das práticas propostas/prescritas pelo mesmo. Nesta perspectiva, entendemos que diferentes práticas engendram objetos sempre diversos, sendo necessário desnaturalizar quaisquer noções totalizantes sobre a infância que se pretendam permanentes e universais, provocando-se, assim, um contínuo questionamento sobre as relações entre saber, poder e verdade.

Para finalizar, gostaríamos de dizer que as problematizações trazidas aqui são um desafio para o campo psi. Concordamos com Coimbra e Leitão (2003) quando concebem o campo das intervenções como um território assumido como político, onde as lutas são cotidianas. Apostamos na proposta transdisciplinar, onde seja possível a "contaminação" com outros saberes, criando outros territórios, outras possibilidades e outras "verdades", entendendo-se aqui que as verdades são sempre provisórias.

\section{Referências}

Ayres, L.S.M. (2001). Os especialistas e a instituição adoção no contexto das políticas públicas de proteção à criança e ao adolescente. Em A.M. Jacó-Vilela, A.C. Cerezzo \& H.B.C. Rodrigues (Orgs.), Clio-Psyché ontem: fazeres e dizeres psi na história do Brasil (pp.249-253). Rio de Janeiro: Relume Dumará; FAPERJ.

Ayres, L. S. M. (2002). Naturalizando-se a perda do vínculo familiar. Em M. L. Nascimento (Org.), Pivetes: a produção de infâncias desiguais (pp. 110-127). Niterói: Intertexto; Rio de Janeiro: Oficina do Autor.

Brasil (1990). Estatuto da Criança e Adolescente, Lei 8.069, de 13 de julho de 1990. Brasília/DF: Author.

Bujes, M.I. (2000). O fio e a trama: as crianças nas malhas do poder. Educação e Realidade, 4(1), 25-44.

Bulcão, I. (2002). A produção de infâncias desiguais: uma viagem na gênese dos conceitos 'criança' e 'menor'. Em M.L. Nascimento (Org.), Pivetes: a produção de infâncias desiguais (pp. 61-73). Niterói: Intertexto; Rio de Janeiro: Oficina do Autor.

Coimbra, C.M.B. (1995). Guardiães da ordem - uma viagem pelas práticas psi no Brasil do milagre. Rio de Janeiro: Oficina do Autor.

Coimbra, C.M.B. \& Leitão, M.B.S. (2003). Das essências às multiplicidades: especialismo psi e produções de subjetividades. Psicologia e Sociedade, 15(2), 6-17.

Coimbra, C.M.B. \& Nascimento, M.L. (2005). Ser jovem, ser pobre é ser perigoso? Consultado em 16/03/2005 de http://

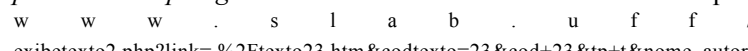
exibetexto2 php?link $=02$ Ftexto 23 htm $\&$ codtexio $=23 \& \operatorname{cod}+23 \&$ tp + + \& nome autor Corazza, S.M. (2000). História da infância sem fim. Ijuí: Unijuí. Fajardo, S. P. (2002). Retórica e realidade dos direitos da criança no Brasil. Em C.M.L. Nahra \& M. Bragaglia (Orgs.), Conselho Tutelar: gênese, dinâmica e tendências (pp. 41-70). Canoas: ULBRA.

Fonseca, C. (2004). Os direitos da criança - dialogando com o ECA. Em C. Fonseca, V. Terto \& C.F. Alves (Orgs.), Antropologia, diversidade e direitos humanos: diálogos interdisciplinares (pp.103-115). Porto Alegre: UFRGS.
Fonseca, C. (1999). O abandono da razão: a descolonização dos discursos sobre a infância e a família. Em E.L.A. Sousa (Org.), Psicanálise e Colonização: leituras do sintoma social no Brasil (pp.255-274). Porto Alegre: Artes e Ofícios.

Fonseca, C. (1995). Os caminhos da adoção. São Paulo: Cortez. Foucault, M. (1984). Vigiar e punir: história da violência nas prisões ( $3^{\mathrm{a}}$ ed.). Petrópolis: Vozes.

Foucault, M. (1996). A verdade e as formas jurídicas. Rio de Janeiro: Nau.

Foucault, M. (2003). Ditos e escritos IV. Michel Foucault. Estratégia, poder-saber (Poder e saber; pp.223-240). Rio de Janeiro: Forense Universitária.

Frota, M. G. C. (2003). A cidadania da infância e da adolescência: da situação irregular à proteção integral. Em A. Carvalho, F. Salles, M. Guimarães \& W. Ude (Orgs.), Políticas públicas (pp.59-86). Belo Horizonte: Editora UFMG.

Gomes da Costa, A.C. (1993). É possivel mudar: a criança, o adolescente e a família na política social do município (Série Direitos da Criança 1). São Paulo: Malheiros.

Gomes, A.M. \& Nascimento, M.L. (2003). Infância, adolescência e proteção: produção histórica e crítica do presente. Em A.M. Jacó-Vilela, A.C. Cerezzo \& H.B.C. Rodrigues (Orgs.), ClioPsyché paradigmas: historiografia, psicologia, subjetividades. (pp.321-326). Rio de Janeiro: Relume Dumará; FAPERJ.

Marcílio, M.L. (1999). A roda dos expostos e a criança abandonada na história do Brasil. Em M.C. Freitas (Orgs.), História social da infância no Brasil (pp.51-76). São Paulo: Cortez.

Martins, C.F. \& Brito, L.M.T. (2001). Resgatando a história da política de atendimento ao adolescente em conflito com a Lei no Brasil. Em A.M. Jacó-Vilela, A.C. Cerezzo \& H.B.C. Rodrigues (Orgs.), Clio-Psyché ontem: fazeres e dizeres psi na história do Brasil (pp.243-248). Rio de Janeiro: Relume Dumará; FAPERJ.

Martins, C.F. \& Brito, L.M.T. (2003). A inserção do psicólogo no sistema de atendimento ao adolescente em conflito com a lei no Brasil. Em A. M. Jacó-Vilela, A. C. Cerezzo \& H. B. C. Rodrigues (Orgs.), Clio-Psyché paradigmas: historiografia, psicologia, subjetividades (pp.371-377). Rio de Janeiro: Relume Dumará; FAPERJ.

Oliveira, L.A. (2001). O laboratório de biologia infantil: discurso científico e assistência no Juizado de menores. Em A.M. JacóVilela, A.C. Cerezzo, A.C. \& H.B.C. Rodrigues (Orgs.), ClioPsyché ontem: fazeres e dizeres psi na história do Brasil (pp.237-242). Rio de Janeiro: Relume Dumará; FAPERJ.

Passetti, E. (1999). Crianças carentes e políticas públicas. Em M. Del Priore (Org.), História das crianças no Brasil (pp.247375). São Paulo: Contexto.

Pinheiro, A.A.A. (2001). A criança e o adolescente como sujeitos de direitos: emergência e consolidação de uma representação social no Brasil. Em L.R. Castro (Org.), Crianças e jovens na construção da cultura (pp.47-68). Rio de Janeiro: NAU.

Pinto, K.P. (2003). Os organizadores da alma popular: educadores, Escola Nova e psicologia no Brasil. Em A.M. Jacó-Vilela, A.C. Cerezzo \& H.B.C. Rodrigues (Orgs.), Clio-Psyché paradigmas: historiografia, psicologia, subjetividades (pp.269-279). Rio de Janeiro: Relume Dumará; FAPERJ.

Rizzini, I. \& Pilotti, F. (1995). A arte de governar crianças História das Politicas Sociais, da Legislação e da Assistência no Brasil. Rio de Janeiro: AMAIS.

Silva Santos, E.P. (2004). (Des)construindo a 'menoridade': uma análise crítica sobre o papel da psicologia na produção da categoria 'menor'. Em H.S. Gonçalves, E.P. Brandão (Orgs.), Psicologia Jurídica no Brasil (pp.205-248). Rio de Janeiro: NAU.

Santos, M.I.F. (2004). Mapeando a realidade de um trabalho voluntário: levantamento estatístico. Em M.R.F. Azambuja, M.V. Silveira \& D.D. Bruno (Orgs.), Infância em família : um compromisso de todos (pp.29-34). Porto Alegre: Instituto Brasileiro de Direito de Família.

Silva, R. (1998). Os filhos do governo: a formação da identidade criminosa em crianças órfãs e abandonadas. São Paulo: Ática.

Venâncio, R.P. (1999). Famílias abandonadas. Campinas: Papirus.

Vianna, A.R.B. (2002). Quem deve guardar as crianças? Dimensões tutelares da gestão contemporânea da infância. Em A.C.S. Lima (Org.), Gestar e gerir: estudos para uma antropologia 
da administração pública no Brasil (pp.271-312). Rio de Janeiro: Relume Dumará.

Volpi, M. (1994). As crianças e adolescentes do Brasil e a luta por seus direitos. Trabalho apresentado no Seminário sobre meninos e meninas de rua. São Leopoldo: Unisinos.
Lílian Cruz é Psicóloga, docente do Departamento de Psicologia (UNISC), doutora em Psicologia (PUCRS). Endereço: UNISC, Av. Independência, 2293, Prédio 35, sl. 3527, 96815-900. Email: liliancruz2@terra.com.br

Betina Hillesheim é Psicóloga, docente do Departamento de Psicologia (UNISC), doutoranda em Psicologia (PUCRS). Email:betinah@unisc.br

Neuza Maria de Fátima Guareschi é Professora/pesquisadora do Programa de Pós-graduação em Psicologia (PUCRS), Coordenadora do grupo de pesquisa Estudos Culturais, Identidades/Diferenças e Teorias Contemporâneas. Endereço: PUCRS, Av. Ipiranga, 6681, Prédio 11, sl. 930, 90619-900. Email:nmguares@pucrs.br

Lilian Cruz, Betina Hillesheim e Neuza Maria de Fátima Guareschi

Infância e Políticas Públicas: Um Olhar sobre as Práticas Psi

Recebido: $29 / 05 / 2005$

$1^{\text {a }}$ revisão: $30 / 09 / 2005$

$2^{\text {a }}$ revisão: $24 / 11 / 2005$

Aceite final: 01/12/2005 